\title{
Application of Box Behnken Experimental Design to Analysis Reaction Conversion of $n$-Butyl Acetate to $n$-Butanol
}

Firuz Fakheri*, Ali Sharif Alam, Shokrollah Mohseni and Ramin Ramezani Kalhor

Shifa Pharmed Industrial Group, Karaj, Iran

\begin{abstract}
In this paper Box Behnken was used to study the effect and optimization of reaction temperature, percentage of $n$-butyl acetate, value of sodium hydroxide on the percentage of reaction conversion of $n$-butyl acetate to $n$-butanol. The mathematical relationship of percentage of reaction conversion on three significant independent variables can be approximated by a nonlinear polynomial model. The analysis of experimental design showed that the percentage of reaction conversion was increased by increasing the temperature and value of $n$-butyl acetate. Results show that the excess value of sodium hydroxide has less effect on the percentage reaction conversion than the other variables and the percentage reaction conversion was found to be strongly affected by the temperature of reaction.
\end{abstract}

Keywords: Reaction Conversion; Box Behnken; $n$-Butyl Acetate; Optimization; Hydrolysis Reaction

\section{Introduction}

Organic solvents are widely used in the pharmaceutical industry. Solvent recovery in pharmaceutical industry is an important plant to reduce operating cost and environmental protection. Purification and recovery of solvents is essential for impurity-free sensitivity standards. During the recovery process chemical reaction is used to remove $n$-butyl acetate from waste $n$-butanol. $n$-butyl acetate cannot be completely removed from $n$-butanol-water mixtures by distillation because of the presence of the minimum ternary azeotrope [1-3].

In this study the parameters affecting the percentage reaction conversion in constant conditions of the experiment are: temperature of reaction $\left(\mathrm{C}^{\circ}\right)$, percentage of $n$-butyl acetate $(\mathrm{v} / \mathrm{v})$, value of sodium hydroxide $(\mathrm{ml})$.

The effect of these parameters may not be independent of each other and it is necessary to consider their interactions. Considerable research has been conducted for determining optimal process parameters. The optimization of the reaction variable has been carried out by using multivariate statistic techniques [4]. Design and methods such as Box Behnken, factorial design and Taguchi methods are now widely used in place of the one factor at a time experimental approach, which is time consuming and exorbitant in cost.

Box Behnken summarized as a collection of statistical tools and techniques for constructing and exploring an approximate functional relationship between an objective function (percentage of reaction conversion) and a set of independent variables. In this technique, the main purpose is to optimize the objective function that is influenced by various operating variables [5].

In this work the objective was to use the Box Behnken Design (BBD) for analyzing and optimizing the effects of the temperature of reaction $\left(\mathrm{C}^{\circ}\right)$, percentage of $n$-butyl acetate $(\mathrm{v} / \mathrm{v})$, value of sodium hydroxide $(\mathrm{ml})$ on the percentage of reaction conversion by using twophase stirred.

\section{Materials and Method}

\section{Box behnken}

Response surface is as a function of independent variables where the response surface can be expressed as follows:

$$
Y=f\left(x_{1}, x_{2}, \ldots ., x_{n}\right)
$$

The goal is to optimize the response variable $\mathrm{Y}$ (percentage of reaction conversion) and $\mathrm{x}_{\mathrm{i}}$, the variables of action called factors. An important assumption is that the operating variables are continuous and controllable by experiments with negligible errors. The design consists of factorial design points with $\mathrm{k}(\mathrm{k}+1)$ runs and $\mathrm{n}$ replications at the center point of the design [4-6].

Among the many types of experimental design models, Box Behnken are commonly used to analysis of factors in three levels three factor experiments. It is necessary to find a suitable approximation for the true functional relationship between independent variables and the response surface. Usually a second-order polynomial Equation 2 is utilized in response surface methodology and is expressed as [7-8]:

$$
Y=b_{0}+b_{1} x_{1}+b_{2} x_{2}+b_{3} x_{3}+b_{11} x_{1}^{2}+b_{22} x_{2}^{2}+b_{33} x_{3}^{2}+b_{12} x_{1} x_{2}+b_{13} x_{1} x_{3}+b_{23} x_{2} x_{3}
$$

Where $\mathrm{Y}$ is the percentage reaction conversion, $\mathrm{b}_{0}$ is the value of fitted response at the center point of design, $b_{1 \ldots . .3}, b_{11 \ldots .33}$ and $b_{12,13,23}$ are the linear, quadratic and interaction terms respectively, and $\mathrm{x}_{1,3}$ the dimensionless coded variables. The second-order model includes all the terms in the first-order model, plus all quadratic terms like $\mathrm{b}_{11} \mathrm{x}_{1}^{2}$ and all cross product terms like $B_{13} x_{1} x_{3}[9,6]$.

\section{Experimental design}

According to the Table 1 the hydrolysis of $n$-butyl acetate to $n$-butanol with sodium hydroxide solution was investigated. In this study hydrolysis reaction with $20 \%$ sodium hydroxide aqueous solution was used to convert $n$-butyl acetate to $n$-butanol. In constant state of reaction the time duration of hydrolysis reaction was 120 minutes. Gas chromatography applied to the quantitative determination of volume percent $n$-butyl acetate in waste water-butanol.

Response surfaces were generated by MINITAB (Demo version 14) statistical analysis software. Statistical analysis of the model was

*Corresponding author: Firuz Fakheri, Shifa Pharmed Industrial Group, Karaj, Iran, Tel: 9367341446; E-mail: eng.fakheri@gmail.com

Received: May 8, 2014; Accepted: August 4, 2014; Published: August 11, 2014 Citation: Fakheri F, Alam AS, Mohseni S, Kalhor RR (2014) Application of Box Behnken Experimental Design to Analysis Reaction Conversion of $n$-Butyl Acetate to $n$-Butanol. J Adv Chem Eng 4: 110. doi: 10.4172/2090-4568.1000110

Copyright: $\odot 2014$ Fakheri $F$, et al. This is an open-access article distributed under the terms of the Creative Commons Attribution License, which permits unrestricted use, distribution, and reproduction in any medium, provided the original author and source are credited. 
Citation: Fakheri F, Alam AS, Mohseni S, Kalhor RR (2014) Application of Box Behnken Experimental Design to Analysis Reaction Conversion of $n$-Butyl Acetate to $n$-Butanol. J Adv Chem Eng 4: 110. doi: 10.4172/2090-4568.1000110

Page 2 of 5

performed to evaluate the analysis of variance (ANOVA). Based on the preliminary experimental results, the levels chosen for the independent variables, Temperature of Reaction $\left(\mathrm{x}_{1}\right)$, Volume of $\mathrm{NaOH}\left(\mathrm{x}_{2}\right)$ and Percent of BA $\left(\mathrm{x}_{3}\right)$ were shown in Table 1. Box Behnken design (BBD) of the experiments was used, where the values of independent variables were coded as the variables, $x$, in the range of +1 and -1 levels. This design was composed of a 12 factorial design (runs 1-12), 3 center points (runs 13-15) thus 15 experiments were needed in total. The mean value of the response (percentage of reaction conversion) obtained under the different experimental conditions are summarized in Table 2. The experimental data (Table 2) were analyzed using statistical methods appropriate to the experimental design used. Replications of factor combinations were necessary to estimate the experimental error [7].

Codification of the levels of the variable consists of transforming each studied real value into coordinates inside a scale with dimensionless values. The variable levels $\mathrm{X}_{\mathrm{i}}$ were coded as $\mathrm{X}_{\mathrm{i}}$ according to the following equation such that $\mathrm{X}_{0}$ corresponded to the central value:

$$
x_{i}=\left(\frac{X_{i}-X_{0}}{\Delta X_{i}}\right) \mathrm{i}=1,2,3, \ldots, \mathrm{k}
$$

Where $\mathrm{x}_{\mathrm{i}}$ is the dimensionless value of an independent variable; $\mathrm{X}$ is the real value of an independent variable; $X_{0}$ is the real value of an independent variable at the center point and $\Delta \mathrm{X}_{\mathrm{i}}$ is the step change [9].

According to Eq. 3, the relations between the coded and the real value were as given below:

$$
x_{1}=\frac{X_{1}-50}{30}, x_{2}=\frac{X_{2}-40}{20}, x_{3}=\frac{X_{3}-7}{3}
$$

\section{Results and Discussion}

\section{Estimated regression coefficient for response and analysis of variance (ANOVA)}

The correlation coefficient may not be sufficient by itself to check

\begin{tabular}{|c|c|c|c|c|c|}
\hline \multicolumn{2}{|c|}{ Temperature of Reaction $\left(\mathbf{C}^{\circ}\right)$} & \multicolumn{2}{|c|}{ Volume of $\mathrm{NaOH}(\mathrm{ml})$} & \multicolumn{2}{|c|}{ Percent of BA\% (v/v) } \\
\hline Real value & Coded value & Real value & Coded value & Real value & Coded value \\
\hline $\mathrm{X}_{1}$ & $\mathrm{x}_{1}$ & $\mathrm{X}_{2}$ & $\mathrm{x}_{2}$ & $\mathrm{X}_{3}$ & $\mathrm{x}_{3}$ \\
\hline 80 & 1 & 60 & 1 & 10 & 1 \\
\hline 50 & 0 & 40 & 0 & 7 & 0 \\
\hline 20 & -1 & 20 & -1 & 4 & -1 \\
\hline
\end{tabular}
the fitted. Thus, ANOVA analysis was also done in this work.

\begin{tabular}{|c|c|c|c|c|c|c|}
\hline \multirow{2}{*}{ Run order } & \multirow{2}{*}{ Block } & \multirow{2}{*}{$x_{1}$} & \multirow{2}{*}{$x_{2}$} & \multirow{2}{*}{$x_{3}$} & \multicolumn{2}{|c|}{ percentage of reaction conversion (\%) } \\
\hline & & & & & Experimental & Predicted \\
\hline 1 & 1 & 0 & -1 & -1 & 14 & 17 \\
\hline 2 & 1 & 1 & 1 & 0 & 100 & 95.2 \\
\hline 3 & 1 & -1 & 0 & -1 & 9 & 1.25 \\
\hline 4 & 1 & -1 & 1 & 0 & 50 & 59.7 \\
\hline 5 & 1 & 1 & 0 & 1 & 91 & 98.7 \\
\hline 6 & 1 & -1 & -1 & 0 & 44 & 48.7 \\
\hline 7 & 1 & -1 & 0 & 1 & 95 & 88.2 \\
\hline 8 & 1 & 0 & -1 & 1 & 74 & 76 \\
\hline 9 & 1 & 0 & 1 & -1 & 27 & 25 \\
\hline 10 & 1 & 1 & -1 & 0 & 96 & 86.2 \\
\hline 11 & 1 & 1 & 0 & -1 & 57 & 63.7 \\
\hline 12 & 1 & 0 & 1 & 1 & 91 & 88 \\
\hline 13 & 1 & 0 & 0 & 0 & 84 & 84 \\
\hline 14 & 1 & 0 & 0 & 0 & 84 & 84 \\
\hline 15 & 1 & 0 & 0 & 0 & 84 & 84 \\
\hline
\end{tabular}

Table 1: Experimental range and levels of the independent variable

Table 2: Parameter levels of Box Behnken (coded value) and the results of experimental and predicted values for percentage of reaction conversion.

\begin{tabular}{|c|c|c|c|c|}
\hline Term & Coef & SE Coef & T & P \\
\hline Constant & 84.00 & 5.612 & 14.967 & 0.000 \\
\hline$x_{1}$ & 30.00 & 3.437 & 8.874 & 0.000 \\
\hline$x_{2}$ & 5.00 & 3.437 & 1.455 & 0.205 \\
\hline$x_{3}$ & 21.75 & 7.719 & 2.818 & 0.037 \\
\hline$x_{1}{ }^{*} x_{1}$ & -21.00 & 5.059 & -4.151 & 0.009 \\
\hline$x_{2}{ }^{*} x_{2}$ & -11.50 & 5.059 & -2.273 & 0.072 \\
\hline$x_{3}{ }^{*} x_{3}$ & 0.00 & 5.059 & 0.000 & 1.000 \\
\hline$x_{1}{ }^{*} x_{2}$ & 1.00 & 4.861 & 0.206 & 0.845 \\
\hline$x_{1}{ }^{*} x_{3}$ & -13.00 & 4.861 & -2.675 & 0.044 \\
\hline$x_{2}{ }^{*}{ }_{3}$ & -0.50 & 4.861 & -0.103 & 0.922 \\
\hline
\end{tabular}

Table 3: Results of the regression analysis of the BBD. 
Citation: Fakheri F, Alam AS, Mohseni S, Kalhor RR (2014) Application of Box Behnken Experimental Design to Analysis Reaction Conversion of $n$-Butyl Acetate to $n$-Butanol. J Adv Chem Eng 4: 110. doi: 10.4172/2090-4568.1000110

Page 3 of 5

Importance of each coefficient was specified by $\mathrm{T}$-values and $\mathrm{P}$-values are listed in Table 3. The larger the magnitude of $\mathrm{T}$-value and the smaller the P-value indicates the considerable significance of the corresponding coefficient [10].

The results of the quadratic and linearity model in the form of ANOVA showed small probability value $(\mathrm{P}<0.1)$ indicating that the all of terms in the model have a significant effect (Table 3 ).

It can be seen that the variables with largest effect were the linear terms $\left(\mathrm{x}_{1}\right.$ and $\left.\mathrm{x}_{3}\right)$ and the quadratic effect of value of sodium hydroxide $(\mathrm{ml})$. Furthermore, the linear effect of the temperature of reaction $\left(\mathrm{C}^{\circ}\right)$, percentage of $n$-butyl acetate $(\mathrm{v} / \mathrm{v})$, the quadratic effect of value of sodium hydroxide $(\mathrm{ml})$ and temperature of reaction $\left(\mathrm{C}^{\circ}\right)$ and interaction terms $\left(\mathrm{x}_{12}\right.$ and $\left.\mathrm{x}_{13}\right)$ are more significant than the other factors, which can be neglected and eliminated from the model. Multiple regression analysis of the experimental data gave the following second order polynomial equation with a $95 \%$ confidence:

$$
Y=84+30 x_{1}+21.75 x_{3}-21 x_{1}^{2}-11.5 x_{2}^{2}-13 x_{1} x_{3}
$$

Table 2 shows the results of Box Behnken design experiments for studying the effect of three independent variables, along with the predicted mean and observed responses.

The fit of the regression model attained was checked by the coefficient of determination $\mathrm{R}^{2}$. The following Figure 1 demonstrates a high degree of correlation between the experimental and predicted values. The value of the determination coefficient $\mathrm{R}^{2}$ (965\%) suggests that only about $3.5 \%$ of the total variation is not explained by the model.

The normal probability plotting of the residuals can be used to checking normality of the data [11]. Figure 2 shows the normal probability plot for the empirical model for percent of conversion. The data shows a straight line in the plot of the residuals, which represents a normal distribution and thus supports the adequacy of the leastsquares fit.

\section{Response surface plots}

The purpose application of the Response Surface Method is to increase efficiency of hydrolysis reaction (Percent of conversion) and to understand how the Percent of conversion changes in a given direction by adjusting the design variables. In general, the response surface can be visualized graphically.

The function percent of conversion can be plotted versus the levels

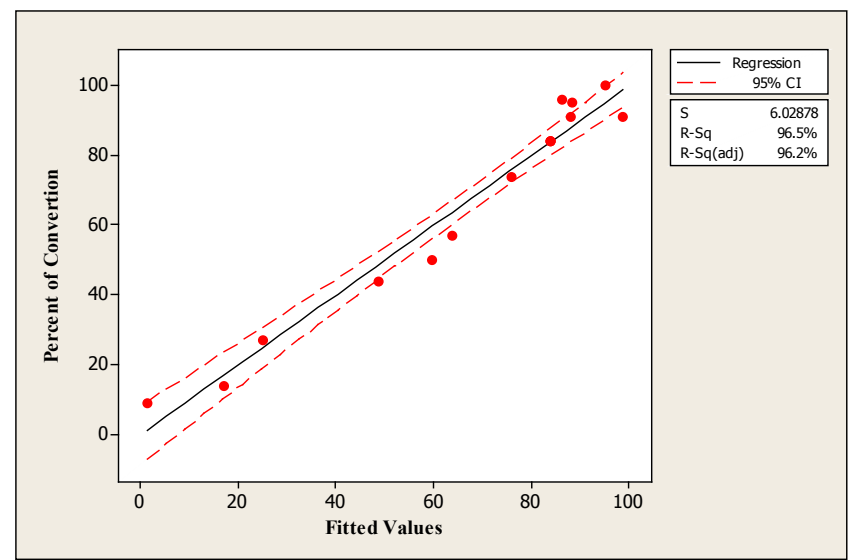

Figure 1: Experimental values and values predicted by Equation (5) of temperature of reaction $\left(\mathrm{C}^{\circ}\right)$, percentage of $n$-butyl acetate $(\mathrm{v} / \mathrm{v})$, and value of sodium hydroxide as shown as Figures 3a-3c. The curvatures in the $3 \mathrm{D}$ plots arise due to the quadratic dependency on response and parameters.

Figure $3 \mathrm{a}$ shows the effect of value of sodium hydroxide and percentage of $n$-butyl acetate on efficiency of hydrolysis reaction

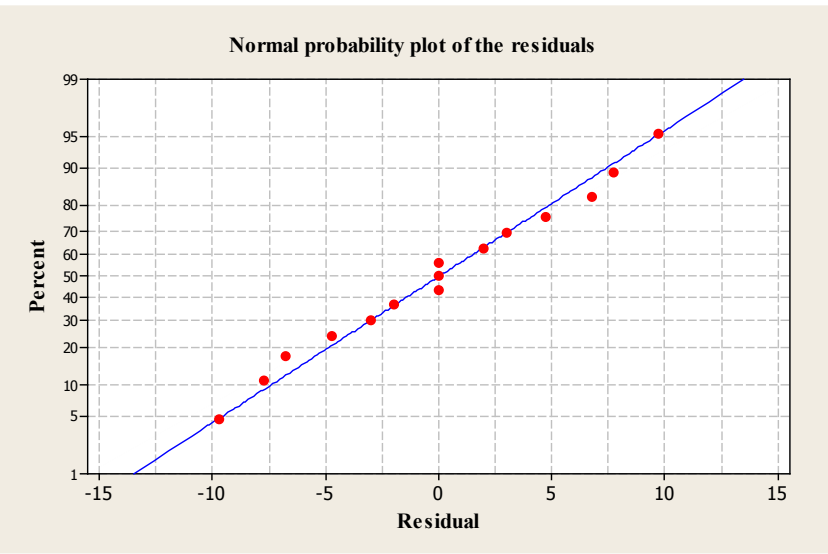

Figure 2: Normal probability plot of the residuals.

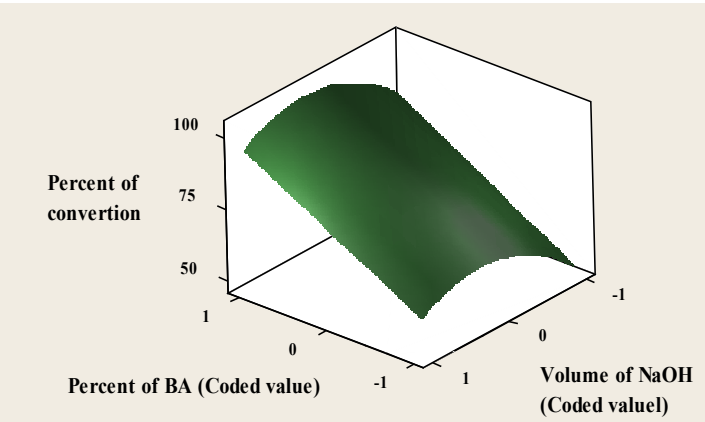

Figure 3a: Effect of Percent of BA and Volume of $\mathrm{NAOH}$ on the Percent of Conversion (Y) in Response Surface (3D) Plot.

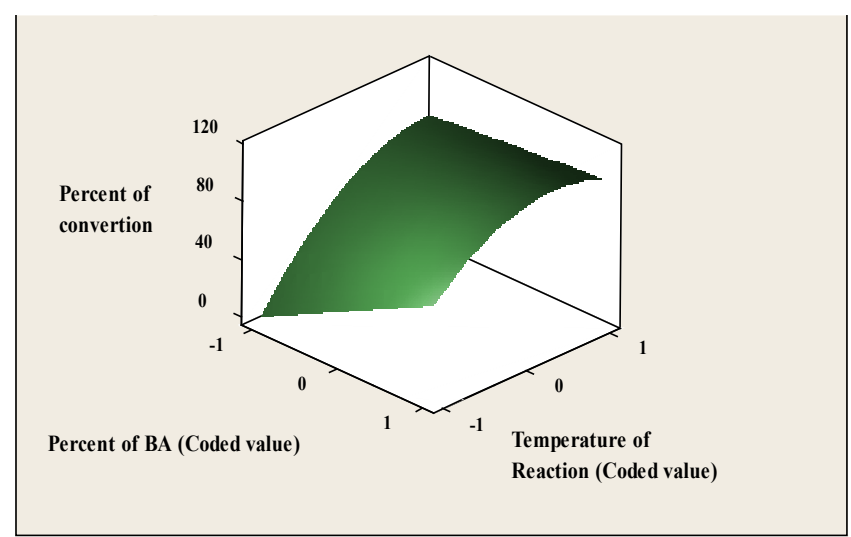

Figure 3b: Effect of Percent of BA and Temperature of Reaction on the Percent of Conversion ( $Y$ ) in Response Surface (3D) Plot. 
Citation: Fakheri F, Alam AS, Mohseni S, Kalhor RR (2014) Application of Box Behnken Experimental Design to Analysis Reaction Conversion of $n$-Butyl Acetate to $n$-Butanol. J Adv Chem Eng 4: 110. doi: 10.4172/2090-4568.1000110

\section{(Percent of conversion).}

The rate of conversion reaction can be increased by increasing the value of sodium hydroxide, except value of sodium hydroxide of about $\mathrm{X}_{2}=50 \mathrm{ml}$ and higher.

The percent of conversion reached the maximum value in the middle level of value of sodium hydroxide. Addition of excess sodium hydroxide wills insignificant decrease the rate of conversion reaction and it caused formation of large amounts of the sodium acetate sediment in stirred reactor. The rate of conversion reaction can be increased by increasing the percentage of $n$-butyl acetate (Figure $3 a$ ).

The maximum value of conversion reaction was detected in a high level of temperature of reaction and percentage of $n$-butyl acetate. Results show that the temperature of reaction has more effect on the rate of conversion reaction than the other variables of the hydrolysis reaction (Figures $3 b-3 c$ ).

Sometimes it is less complicated to view the response surface in two-dimensional graphs. The contour plots can show the contour lines of the independent variables that have the same response value $Y$. From the response surface contour plots, it is very easy and convenient to understand the interactions between two independent variables and also to locate their optimum levels.

Figures $4 \mathrm{a}-4 \mathrm{c}$ shows the contour plots of percent of conversion for each pair of parameters. An elliptical contour plot indicates that the interactions between them are significant. In Figure $4 \mathrm{~b}$ indicating that there were significant interactions between the temperature of reaction and percentage of Butyl Acetate.

\section{Conclusions}

In this work, the effects of three experimental parameters on the percent of conversion were investigated statistically. BBD was used to design an experimental program for to analysis reaction conversion of $n$-butyl acetate to $n$-butanol. In this model the parameters affecting the reaction conversion in constant conditions of the experiment were: the temperature of reaction $\left(\mathrm{x}_{1}\right)$, value of sodium hydroxide $\left(\mathrm{x}_{2}\right)$ and percentage of $n$-butyl acetate $\left(\mathrm{x}_{3}\right)$. Mathematical model equations were derived for the percent of conversion by using the experimental data and the mathematical software package MATLAB (Demo version 14). The adequacy of the predictive model was verified effectively by the validation data. Predicted values were found to be in good agreement with the experimental values. In order to gain a better understanding of the three variables for optimal percent of conversion performance, the models were presented as 3-D response surface graphs. The optimum process parameters for percent of conversion were obtained

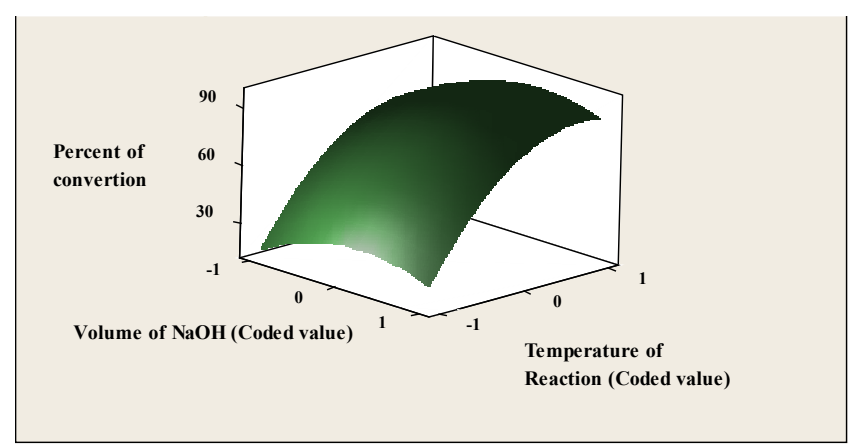

Figure 3c: Effect of Volume of $\mathrm{NAOH}$ and Temperature of Reaction on the Percent of Conversion ( $Y$ ) in Response Surface (3D) Plot.

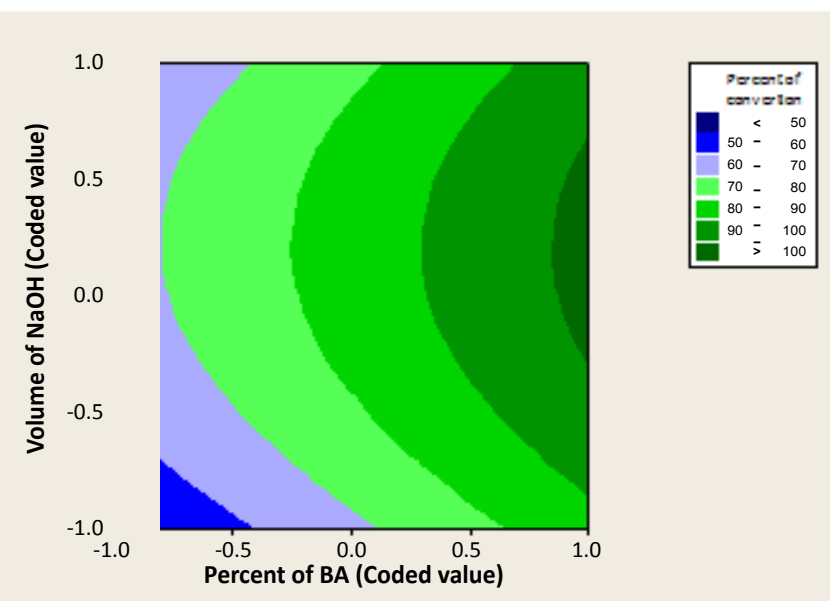

Figure 4a: Effect of Percent of $\mathrm{BA}$ and Volume of $\mathrm{NAOH}$ on the Percent of Conversion (Y) in Contour (2D) Plot.

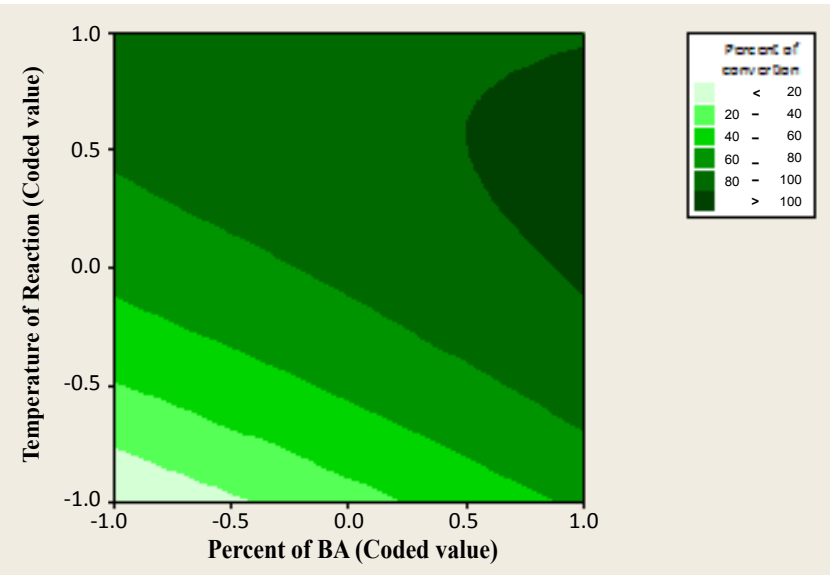

Figure 4b: Effect of Percent of BA and Temperature of Reaction on the Percent of Conversion (Y) in Contour (2D) Plot.

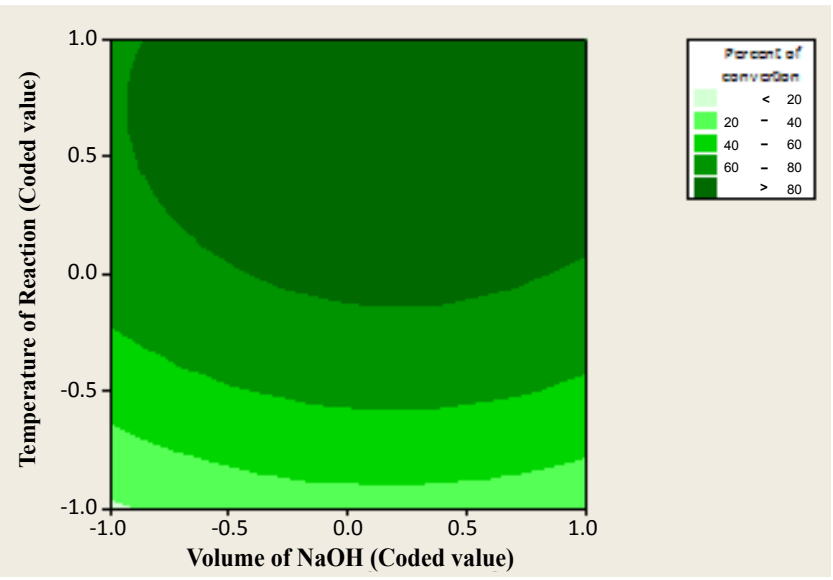

Figure 4c: Effect of Volume of $\mathrm{NAOH}$ and Temperature of Reaction on the Percent of Conversion (Y) in Contour (2D) Plot.

as: temperature of reaction, $65^{\circ} \mathrm{C}$; value of sodium hydroxide, $40 \mathrm{ml}$ and percentage of $n$-butyl acetate, $8 \% \mathrm{v} / \mathrm{v}$. The values of R-squared 
Citation: Fakheri F, Alam AS, Mohseni S, Kalhor RR (2014) Application of Box Behnken Experimental Design to Analysis Reaction Conversion of $n$-Butyl Acetate to $n$-Butanol. J Adv Chem Eng 4: 110. doi: 10.4172/2090-4568.1000110

Page 5 of 5

$\left(\mathrm{R}^{2}=0.965\right)$ is close to 1 , indicating a high degree of correlation between the response and the independents variables in two responses (experimental and predicted values). The value of the determination coefficient $\mathrm{R}^{2}(965 \%)$ suggests that only about $3.5 \%$ of the total variation are not explained by the model.

\section{References}

1. Liua K, Tongb Zh, Liua L, Feng X (2005) Separation of Organic Compounds from Water by Pervaporation in the Production of $n$-Butyl Acetate via Esterification by Reactive Distillation. J Membrane Sci 256: 193-201

2. http://www.aiche.org/resources/publications/cep/2009/march/selectingentrainers-azeotropic-distillation

3. Berg L,Yeh A, Bozeman M (1985) Separation of n-butyl acetate from n-butanol by extractive distillation. U.S. Patent 4525245 .

4. Kwak JS (2005) Application of Taguchi and response surface methodologies for geometric error in surface grinding process. Int $\mathrm{J}$ Machine Tools and Manufacture 45: 327-334.

5. Venter G (1998) Non-dimensional response surfaces for structural optimization with uncertainty. PhD Thesis, University of Florida.

6. Bradley N (2007) The response surface methodology. PhD Thesis, Indiana University, South Bend.

7. Açikalin K, Karaca F, Bolat E (2005) Central composite rotatable design for liquefaction of pine barks. Fuel Process Technol 87: 17-24.

8. Aslan N (2007) Application of response surface methodology and central composite rotatable design for modeling the influence of some operating variables of a Multi-Gravity Separator for coal cleaning. Fuel 86: 769-776.

9. Tanyildizi MS, Ozer D, Elibol M (2005) Optimization of -amylase production by Bacillus sp. using response surface methodology. Process biochemistry 40 2291-2296.

10. Karthikeyan RS, Rakshit SK, Baradarajan A (1996) Optimization of batch fermentation conditions for dextran production. Bioprocess Biosyst Eng 15 247-251.

11. Pokhrel D, Viraraghavan $T$ (2006) Arsenic Removal from Aqueous Solution by Iron Oxide-Coated Fungal Biomass: A Factorial Design Analysis. Water Air \& Soil Pollution 173: 195-208. 